\title{
Joining the Global Elites: Dilemmas for China in Reforming its Systems of Scientific and Technological Innovation
}

\author{
By
}

\section{Shaowei He and Richard Sanders}

\section{Introduction}

China presents us with many puzzles. Is it a developed or still developing economy, is it capitalist or communist, planned or market led? Many of these puzzles find resonance in the country's latest scheme to attract global scientific elites for not only does the initiative represent China's strategy to reform its national innovation system, but it also offers a lens through which to understand this huge and dynamic country and an opportunity to confront the puzzles within it.

\section{The Transition of the Chinese Economy and its Systems of Innovation}

China has maintained very rapid economic growth and development over the last three decades, indeed the scale and speed of economic growth, at approximately $9 \%$ per annum since 1980, is nothing short of heroic (it must be remembered that the only country in modern times to achieve anything close to such rates of GDP growth -Japan between the 1950 and 1970 s - . has a population one tenth the size of China's). Economic reforms, including the launch of the 'open door' policy in the early 1980's and the accession of China to the World Trade Organisation in 2001 have paved the way for this extraordinary performance and the country has now re-emerged - after many centuries - as a major power in the world economy. In purchasing power parity (PPP) terms, China is now the second largest economy in the world and is, now, not only a major destination for foreign direct investment but also a source as Chinese companies export increasing amounts of capital abroad. Although GDP per capita is still low compared to the OECD average, recent economic growth in China has nonetheless allowed more of the world's population to escape poverty than at any other time in human history.

Underlying China's impressive achievement has been a fundamental and ongoing reform of all aspects of the society and in particular of the economic system itself. In contrast to the 'big-bang' model adopted by the economies of the former Soviet Union and Eastern Europe in the 1990s, China has taken a gradual, pragmatic and experimental approach to reform ("crossing the river by feeling the stones"), leading to the parallel existence of a planned and a market economy. While some observers argue that this gradual approach has focused on changes at the microeconomic level, delaying reforms in the macroeconomic environment (OECD, 2008a), the overall scale, scope and success of the reforms in achieving material economic progress is undeniable.

In parallel to China's economic reforms has been a modernisation strategy which emphasises science and technology and enlarging the innovative capacity of Chinese industry. Thus, China is not satisfied with merely becoming the (low-tech) 'workshop of the world'. In practice, when the Chinese leadership called for reforms to modernise the country as early as the mid 1970s - 'the four modernisations' - they specifically referred to the modernisation of industry, agriculture, national defence and science and technology. Since then, great efforts have been undertaken to reform the educational system not only to supply the required skills but also to foster students' creativity. A range of initiatives have been set 
up to encourage firms in acquiring and absorbing imported technologies. Meanwhile, reforms have also been made to strengthen cooperation between the science and technology community and the industrial sector by 'breaking the vertical separation of the old R\&D and production systems under the planned economy and stimulating market-based relationships between the two sectors' (OECD, 2008a: 426). In 1995, the authorities launched a strategy of 'revitalising the country with science, technology and education (kejiao xing guo), attaching great importance to the role of science and technology in stimulating growth and development.

More recent years have seen an increasing pace in the mobilisation of resources to further upgrade China's innovation capacity. Apart from continuously seeking better access to global knowledge and technologies, China has focused on becoming part of what has been seen as a new global knowledge-based elite network based on science and technology, to include ICT and biotechnology.

Thanks to the government's rapid, decades-long commitment to research and development (R\&D) expenditure, China's $R \& D$ intensity - R\&D expenditure as a share of GDP - reached $1.42 \%$ in 2006, up from $0.7 \%$ in 1998. Indeed, since 1999, China's spending on R\&D has increased by more than $20 \%$ each year (Wilsdon and Keeley, 2007). As a result of the market-oriented reforms, industry has begun to play a major role in the R\&D system. In addition to the rapid increase in R\&D expenditure, China has become home to the world's second largest stock of science and technology personnel, second only to the United States (OECD, 2008b). Attracted by the quality of human resources for science and technology and the massive Chinese market, there has been a strong increase in $R \& D$ investment by foreign firms in the last decade there.

Science and technology outputs have also grown, although sometimes not at the same pace as inputs. China has become a large exporter of high technology products. It has jumped from $13^{\text {th }}$ place in the mid 1990 s to $4^{\text {th }}$ place in terms of share of world total publications (CREST, 2007). The following table illustrates some of the important achievements China has made over the last fifteen years.

Table 1 China's science and technology inputs and outputs

\begin{tabular}{|l|l|l|}
\hline & Quantity & Year \\
\hline \% GDP spent on R\&D & $\begin{array}{l}0.7 \% \\
1.42 \%\end{array}$ & $\begin{array}{l}1998 \\
2006\end{array}$ \\
\hline S\&T workforce & $\begin{array}{l}2.25 \text { million scientists and } \\
\text { engineers }\end{array}$ & 2004 \\
\hline $\begin{array}{l}\text { Enrolment in tertiary } \\
\text { education }\end{array}$ & 15 million & 2004 \\
\hline $\begin{array}{l}\text { Number of colleges and } \\
\text { universities }\end{array}$ & 1731 & 2004 \\
\hline $\begin{array}{l}\text { Number of scientific } \\
\text { publications (in SCI) }\end{array}$ & 13,500 & 1995 \\
\hline $\begin{array}{l}\text { Share of world citations } \\
46,000\end{array}$ & $\begin{array}{l}0.92 \% \\
3.78 \%\end{array}$ & 2004 \\
\hline $\begin{array}{l}\text { Applications for invention } \\
\text { patens }\end{array}$ & 130,000 & 2005 \\
\hline $\begin{array}{l}\text { Growth rate of invention } \\
\text { patent applications }\end{array}$ & $23 \%$ annually since 2000 & 2005 \\
\hline
\end{tabular}




\begin{tabular}{|l|l|l|}
\hline $\begin{array}{l}\text { Inflows of foreign direct } \\
\text { investment }\end{array}$ & $\$ 72.6$ billion & 2005 \\
\hline $\begin{array}{l}\text { Multinational R\&D } \\
\text { centres in China }\end{array}$ & 750 & 2005 \\
\hline
\end{tabular}

Source: adapted from Wilsdon and Keeley, 2007

Indeed such is the pace of China's progress in upgrading its innovation capacity that the OECD (2008a) has ranked the country as the second largest R\&D spender in terms of purchasing power parity, just behind the U.S. Commentators have begun to consider whether or not China is destined to become the next scientific superpower (e.g. Wilsdon and Keeley, 2007).

Although the transition and upgrading of the Chinese economy and its innovation system has been impressive, there remain tremendous challenges facing the country. In particular, it has been pointed out that it is extremely difficult to maintain sustainable development with its current growth model based as it is on 'a combination of low-cost manufacturing, imported technology and substantial flows of foreign investment' (Wilsdon and Keeley, 2007). Major challenges include income inequality between urban and rural areas and also between the western and eastern parts of the country, fundamental demographic shifts owing to a rapidly ageing population and environmental and ecological challenges caused by rapid economic growth, industrialisation and urbanisation (OECD 2008a).

With regard to China's system of scientific and technological innovation, universities have been struggling with a dramatic expansion of students, with considerable concern about the mismatch between the quality of the graduates and the skills demanded in the labour market. In addition, despite a rapid increase of $R \& D$ investment in the business sector, $R \& D$ expenditure as a share of value-added remains low (CREST, 2007). Partly because of this, China is still unhealthily reliant on foreign technologies. Indeed, a large share of China's high tech export is based simply on the assembly of imported high-tech components.. It is reported, furthermore, that only $0.03 \%$ of Chinese firms own the intellectual property rights of the core technologies they use (Wilsdon and Keeley, 2007).

The Chinese authorities are well aware of the challenge of making the country's future development economically, socially and ecologically sustainable, and of achieving a more balanced pattern of development. They acknowledge, in particular, that developing innovation capacity can significantly help to escape from the 'low-end path' of development characterised by intensive use of low-skilled labour and natural resources and the low level of technological capabilities so characteristic of the early years of reform. They have taken steps, through pushing concepts such as 'the harmonious society' and 'the innovative economy', to shift towards a new development model and to achieve greater social, ecological and environmental sustainability.

\section{The internationalisation of innovation and the search for global scientific elites}

To many observers, globalisation in the last several decades has involved developing countries, particularly Asian economies, building up their industrial production capacities rapidly while innovation activities have remained concentrated in OECD countries. This is beginning to change. Indeed, in recent years, the world has experienced an increasing trend towards the internationalisation of science, technology and innovation, manifested by the rapidly growing volume of cross-border technology transfer, joint generation of knowledge to include international co-publications and co-patenting activities, off-shoring of corporate 
R\&D activities and increased mobility of science and technology personnel, all increasingly involving developing countries (see, for example, UNCTAD, 2005; OECD, 2008b).

Increased mobility of such personnel is part of the process of the internationalisation of innovation. The movement of highly skilled people has intensified as economic activity becomes ever more globalised. Moreover, the growing emphasis of knowledge means that countries across the world have a greater appetite for highly skilled specialists who are able to understand, access and exploit knowledge and consequently contribute to innovation and economic prosperity.

It is no surprise therefore, although less well-reported than the competition for raw materials and capital, that there has also been increasing competition between countries and between firms for highly skilled people. Against the background of the internationalisation of innovation, many countries have set up schemes to attract top scientists and researchers and encourage international mobility of highly skilled people. The European Union Scientific and Technological Research Committee reported that the majority of its member states have national policy measures in place to enhance the mobility of researchers through governmental funds (CREST, 2007). Finland, for example, launched a new funding programme to recruit foreign top researchers in 2005. Similar polices have been found in other countries (OECD 2008b, OECD2008c).

Developing countries such as China and India have recently joined the developed world to include the USA, the EU, Japan, Canada and Australia in chasing highly skilled people (Wyckoff and Schapper, 2005). China, in particular, has scaled up its efforts recently and has targeted the large pool of talent amongst the more than one million mainland Chinese who have travelled abroad to study and work. China has recognised that the networks maintained by repatriates with their former host country can be vital to knowledge creation and transmission. Using examples from India, China, Malaysia and Chinese Taipei, research has shown that highly-skilled repatriates have played a key role in developing hightechnology sectors in these countries (Lazonick, 2007; Saxenian, 2006).

In the 1990's, there were a number of high-profile schemes initiated in China by some of the key science and technology institutions for returnees. For example, the Ministry of Education launched the Chung Kong scholarship in 1998 to encourage overseas Chinese scholars to return to China, funded by a Hong Kong billionaire. In the following ten years, 115 universities participated and recruited 1308 professors from overseas, 38 of whom have become academicians of either the Chinese Academy of Science (CAS) or the Chinese Academy of Engineering (CAE). Meanwhile the CAS itself initiated the 'One Hundred Talent Programme' in 1994 which offered promising scientists under the age of forty-five 2 million RMB (approximately $£ 200,000$ ) in the form of research funding, equipment expenditure and housing benefit in order to lure them back to China. This scheme funded more than 1300 highly skilled returnees, among whom 20 have become Academicians of the CAS $^{1}$. The National Natural Science Fund's 'Distinguished Young Scholars' offered similar incentives to overseas Chinese scientists who were willing to return. There have been other smaller scale programmes from various science and technology institutions. Moreover, provincial and regional government have also introduced their own initiatives to encourage the return of overseas scholars and graduates.

While there have been some successful initiatives in the past, the Chinese authorities' efforts to lure back repatriates have intensified in recent years. Incentives offered to returnees now include low-interest loans and high salaries, government subsidies, tax deductions, IPR incentives and priority employment for spouses and education enrolment for children (CREST, 2007; OECD, 2008a). Highly skilled returnees are also exempt from the household

\footnotetext{
${ }^{1}$ http://news.sciencenet.cn/htmlnews/2009/216387.html.
} 
registration system - the hukou - and therefore are able to choose to live and work wherever they like.

Despite the lucrative incentives, however, the results of these initiatives to date appear to be rather mixed. On the plus side, according to the Ministry of Education, $77 \%$ of the presidents of Chinese universities, $84 \%$ of the academicians at the CAS, $75 \%$ of the academicians at the CAE have overseas study and/or work experience ${ }^{2}$. But while the government schemes mentioned above have attracted some top scientists back from abroad, the number of returnees still falls short of what is needed (OECD, 2008a). Indeed, the Communist Party's Central Personnel Department, in charge of policy making and the implementation of senior level human resource management, has admitted that the quantity and quality of the returnees is still far from meeting the future needs of China. In particular, the country is still short of top scientists who are able to make scientific breakthroughs in key areas. Meanwhile, among those who have returned, it is claimed that some were merely opportunists pursuing windfall benefits.

Looking at the broader picture, it has been reported that, altogether, about 319,700 overseas gradates have returned between 1978 to $2007^{3}$. However, this still means that about $75 \%$ of the over 1 million Chinese who have studied or are studying abroad have not returned home. The number of returnees falls short of what would be needed to significantly reduce the current and prospective shortages of certain types of skills (OECD, 2008a). It is widely assumed that those who remain overseas include many of the best and brightest (Wilsdon and Keeley, 2007; Cao, 2007). And some of the latest news suggest that things are not getting any better. It is reported that since 1985, Tsinghua University and Beijing University, the two most prestigious universities in China, have seen, respectively, $80 \%$ and $76 \%$ of their science graduates leaving for the United States. In 2006, they became the top two suppliers of $\mathrm{PhD}$ students in the U.S. surpassing University of California at Berkeley.

China has certainly felt the pain of this brain drain and the urgency to lure back more expatriates has become ever more acute in the context of the authorities' push for innovation. The Chinese government plans to raise R\&D intensity from $1.42 \%$ of GDP in 2005 to $2 \%$ in 2010 and $2.5 \%$ in 2020 . However, there remains a great deal of tension between the push for innovation and the capacity of the system to deliver it. The OECD estimates that China needs an additional 2.6 million researchers over and above the numbers in 2005 in order to meet the target of $2.5 \%$ R\&D intensity by 2020 and that there will be large gap even if the current level of growth in the absolute number of researchers is maintained (OECD, 2008a). Recognising that the country lacks scientific leadership and that its national innovation system is intimately embedded in global networks and flows of knowledge, capital and talent, the Chinese authorities have now decided to launch a new flagship initiative to attract top scientists from overseas. Acknowledging that innovation plays a key role in future sustainable development, China has stepped up its efforts in human capital formation and in the enhancement of its capabilities in science, technology and innovation. Thus, one of the most recent and striking schemes has been a flagship initiative called the 'One Thousand Talents Scheme' with the aim of attracting global scientific elites - and particularly those of Chinese origin - back to China.

\section{The One Thousand Talents Scheme and global scientific elites}

Chinese leaders since the inception of the Peoples Republic in 1949 have always displayed a strong commitment to science and technology. However their beliefs in the power of science

\footnotetext{
${ }^{2} \mathrm{http}: / /$ news.sciencenet.cn/htmlnews/2009/216387.html.

3 http://news.sciencenet.cn/htmlnews/2009/216387.html.
} 
and technology to deliver social and economic progress have become ever stronger as more and more of its current leaders have been trained in science and technology subjects. With the acknowledgment of the challenges in securing sustainable development and a strong faith in science, technology and innovation to help China overcome these challenges, the State Council, on 9 February 2006, outlined the Medium to Long Term National Plan for the Development of Science and Technology (2006-2020). The overarching aim of the plan is to boost the country's innovation capacity to sustain economic growth and development and at the same time to provide technological solutions to social and environment challenges. Apart from reform programmes in intellectual property rights, scientific institutions and industrial innovations, the Plan identifies a number of key science and technology priorities and aims to increase China's spending on science to $2 \%$ of its GDP in 2010 and $2.5 \%$ in 2020, by which time the country will have become an 'innovation-oriented economy'.

Following up the Medium to Long Term Plan, the Central Organisation Department of the Chinese Communist Party launched the 'One Thousand Global Talents Scheme' to help China make the transition from the 'workshop of the world' to an 'innovation-orientated economy'. The scheme represents China's latest effort in a global hunt for top-notch talents and plans to recruit 2,000 talents of any nationality (but particularly targeting overseas Chinese) in the next five to ten years. Candidates will normally be under 55 years old and hold an overseas doctorate degree. They should also fulfil one of the following criteria: (1) have an academic title equivalent to professor in internationally renowned universities and research institutions; (2) work as a senior manager or professional within a well-known international company or finance institution; (3) have developed technologies and patents and established their own businesses abroad or (4) have other highly innovative or entrepreneurial talents.

According to the scheme, there are four recruitment routes:

1. Via national key innovation projects: talents via this platform will be recruited for the national key scientific projects specified in the Medium to Long Term National Plan for the Development of Science and Technology (2006-2020) and another two key national basic research projects called 863 and 975 projects. The Ministry of Science and Technology will administer the candidate application and evaluation processes;

2. Via key scientific subjects and laboratories: these are to recruit talents for universities and key national scientific laboratories, which are administered by the Ministry of Education and Ministry of Science and Technology respectively;

3. Via enterprises (with an emphasis on state-owned enterprises) and finance institutions. The processes are administered by the State-owned Assets Supervision and Administration Commission and the People's Bank of China respectively;

4. Via high-tech parks: these are to attract returnees to set up businesses in various types of high-tech parks. The process is administered by the Ministry of Science and Technology and Ministry of Human Resources;

Since it was launched in early 2009, the scheme has recruited 825 talented individuals. It is noticeable that, although the scheme has a focus on Chinese expatriates, it does not exclude top talents of non-Chinese origin. Indeed, among the latest list of 163 recruited talents, 104 hold foreign passports and 3 are of non-Chinese origin.

It is easy to find close links between the scheme and the Medium to Long Term National Plan for the Development of Science and Technology (2006-2020). The scheme is viewed as a strategic action to transform China into an 'innovation-oriented country'. There is a strong emphasis that the scheme should serve the national science and technology 
objectives and that it should recruit 'strategic scientists' and science and technology leadership to help bring forward breakthroughs in key scientific areas and develop high-tech industries.

It is a high-profile flagship scheme in at least two senses. Firstly, it targets global scientific talents who are able to bring achieve scientific breakthroughs and offer scientific leadership as mentioned above. Secondly, the scheme offers global competitive financial incentives including a 1 million RMB relocation packages on top of normal salaries, research funding, hukou exemptions and preferential visa policies and medical services for the talents and their relatives.

Arguably, the recruited top talents are joining a prestigious group of scientific elites, giving them enormous power in the elaboration and orientation of science and innovation policies in China. Firstly, they are offered the title of National Prestigious Professor, giving them very high social status. Secondly, they are able to access many resources not available to the general scientific public. For example, many of them are offered senior management roles in universities, research institutions, state-owned enterprises and finance institutions. Some are also able to take leadership roles in key national scientific projects. Last but not the least, they are connected to the Communist Party leadership via the Party's Central Talents Coordinating Group, which coordinates national policy-making in the human resources area and is headed by the CCP's powerful Central Personnel Department. The latest manifestation of this is the Party's invitation to 70 scientific elite personnel associated with this scheme to enjoy a week's holiday at Beidaihe, a traditional tourist resort for the Party leadership. During their stay, three members of the Politburo of the Party's Central Committee (which includes the most powerful twenty five people in China) including Xi Jinping, the likely successor of current Chinese President, Hu Jintao, paid them a visit and held conversations with them.

\section{Continuing Challenges}

It is reported that since the launch of the scheme, more than 100,000 expatriates have returned to China in 2009 alone $^{4}$. It seems that this high-profile project has had a rippling effect. However, there are still significant challenges for the Chinese authorities to identify and recruit the right candidates and for the recruited scientific elites to achieve significant scientific breakthroughs and offer scientific leadership and consequently to boost China's innovation capacity.

\subsection{Challenge 1: Innovation takes more than Investment}

According to Wilsdon and Keeley (2007:61) "China has a focused and strategic approach to science and innovation policy, which is being supported by dramatic increases in funding at every level, and in the overall share of GDP devoted to R\&D." Mobilising resources is obviously one of the strengths of the Chinese innovation system. The 'One Thousand Talents Scheme' is timely as most of the developed countries are hit by the financial crisis and cutting education and research budgets. China, in contrast, continues to invest in science and technology and is now able to offer talents globally competitive salaries. However, there is still the question as to whether China is able to lure the 'best and brightest' Chinese who are still overseas and allow those who have returned to flourish. This depends not only on investment in 'hardware' and infrastructure for innovation, but also on improvements in 'software' and the culture for innovation, particularly with respect to the environment,

\footnotetext{
${ }^{4}$ See http://www.1000plan.org/qrih/article/4923.
} 
entrepreneurship, creative culture, and wider political reform (OECD, 2008b; Wilsdon and Keeley, 2007; Leadbeater and Wilsdon, 2007). However, there are worrying signs in this regard.

Firstly, it is widely accepted that innovation and creativity depends on openness and the freedom to debate and disagree. The Chinese education system, however, despite recent reforms still encourages largely passive learning. More worryingly to some observers is the fact that the Chinese authorities seem to be tightening censorship of the media and the Internet, illustrated, for example, in the recent battles between China and Google over the control of Internet and information ${ }^{5}$. To many, the excessive efforts by the Chinese authorities to tighten censorship is in direct conflict with its desire to encourage science and innovation, with the practice of restricting access to the Internet and information having negative repercussions in the longer term.

Secondly, there has been a widespread campaign across Chinese universities and research organisations for more international publications, especially in journals included in the Science Citation Index 6 . However it could be argued that scientific institutions in China place more emphasis on quantity rather than quality, evaluating and rewarding their scientists accordingly. As spending on R\&D has increased, so have the society's expectations for the scientists.

No doubt elite membership of the 'One Thousand Talents Scheme' is 'a stepping stone for controlling resources and for gaining material privileges' (Cao, 2010), but the talents recruited via the scheme will soon face mounting pressure on 'visible' outcomes. And the increasing incidence of academic fraud and corruption in recent years testifies to this mounting pressure for 'visible' outcomes and quantity, associated with an erosion of Chinese traditional values and ethics. The most notorious example in recent years involved Jin Chen, Dean of the Microelectronics School at Shanghai Jiaotong University, who claimed to have developed a groundbreaking microchip and subsequently received over $£ 7.5$ million in research grants. Dr. Chen was highly praised by the top Chinese leadership for his alleged technological breakthrough, which was found later to have been fraudent, based as it was on reusing Motorola's chips, from which he had simply erased the original logo and to which he had added that of his own company ${ }^{7}$.

Unfortunately, the case of Dr. Chen is only the tip of the iceberg of academic misconduct in China. According to the Chinese Association for Science and Technology, more than $55 \%$ of Chinese scientists who responded to its recent survey indicated that they knew colleagues who were involved in academic misconducts cases to include plagiarism and fraud. More worryingly, more than $30 \%$ of the respondents were sympathetic to the offenders ${ }^{8}$.

There is therefore a question as to whether the scientific elites recruited via the 'One Thousand Talents Scheme' are able to transplant the norms and values of the world's learning centres of innovation, to which they have been long exposed, to an environment so different from those centres. Apart from the cultural shock in dealing with the established hierarchy in the established innovation community, they will find themselves in a less open, more closely knit and more quantity and materially-driven society. Because of this there has already been warnings that without further reform in China towards a more transparent, open, and

\footnotetext{
${ }^{5}$ See for example, analysis in Econmist.com http://www.economist.com/node/15267915?story id=15267915

${ }^{6}$ A bibliometric database complied by Thomson Reuters.

${ }^{7}$ McGregor, R, 'Fake chip storm shocks China's scientific elite', Financial Times, 15 May 2006.

${ }^{8}$ http://www.cast.org.cn/n35081/n35593/n38830/11418132.html.
} 
autonomous innovation system, the recruited 'One Thousand Talents' could soon flee away from China again to whence they had been recruited ${ }^{9}$.

\subsection{Challenge 2: Political Problems}

According to Leadbeater and Wilsdon, (2007) China is attempting an authoritarian modernisation combining markets and Communist rule. It is not difficult to find evidence of this nor is it difficult to find evidence of the influence of the ubiquitous shadow of politics on the implementation of the 'One Thousand Talents Scheme'. The fact that the Communist Party's Central Personnel Department is in charge of the scheme is closely in line with the Party's basic principle of 'the Party controlling human resources'. Li Yuanchao, Head of the Central Personnel Department and one of the members of the Party Politburo of the Central Committee, sees the scheme as his own initiative and wants it to work well at least partly if not entirely so that he will be in an advantage position in the forthcoming leadership reshuffle in 2012.

Since the launch of the scheme in early 2009, many provincial and regional governments have developed their own talent initiatives in line with the central scheme, as required by the Party and the central government. The Governors and Party Generals in the provinces and regions also have an interest in recruiting as many talents as possible, with the aim of winning the support of Li Yuanchao in their own political ascendancy bids.

With so much politics at stake, it is no wonder that we have witnessed so much enthusiasm for the scheme, yet so much politically-inspired enthusiasm may well be ultimately detrimental to it and to the Chinese innovation system more generally. For example, this enthusiasm has led to an almost unseemly rush for global scientific talents with the scheme being viewed as a political task. Consequently, there is a risk that some will be (have been?) recruited without much assessment. By the end of 2009, the scheme had already recruited 326 people. However, there is criticism over the rigour of the evaluation process with some organisations being preoccupied with meeting targets rather than with ensuring that the recruits have the appropriate expertise. It was reported that the second round of recruitments of the scheme, for example, took less than three months from application to the end result and that candidates were evaluated only on the basis of their application forms and without an interview process ${ }^{10}$.

Another problem with such overt political involvement is that it may, in the end, stifle innovation. Many of the recruited talents will be put in important positions such as school deans or heads of research institutions. Some of them may even rise to positions at ministerial level, as did Wang Gang who worked for Audi in Germany for 15 years before returning in 2004 and becoming, as he is today, Minister of Science and Technology. Indeed, as Xi Jinping emphasised when he visited Beidaihe recently, the recruited talents will be offered key positions, will participate in key decision making, and lead key scientific subjects. And associated with these administrative and management roles come political opportunities. No doubt some will become members of the Chinese Communist Party or be selected as deputies to the National People's Congress (NPC) or members of the Chinese People's Political Consultative Conference (CPPCC), the country's highest legislative body and political consultation organisation. Apart from the requirement that they attend annual sessions, this will give them the opportunity to be included in the nation's political process, involving them in decision making, legislation and consultation and advisory work.

\footnotetext{
${ }^{9}$ www.93.gov.cn/partic/sugges/1272854526398831246.shtml.

${ }^{10} \mathrm{http}: / /$ news.sciencenet.cn/htmlnews/2010/3/229438.shtm.
} 
The disadvantage for the scientific elites of taking administrative, management and political roles is that they have to spend a great deal of time looking after guanxi (relationships) internally and externally and therefore have little time for research and innovation, as illustrated in Cao and Suttmeier's (2001) study on Chinese scientific elites. In addition, many have argued that the privileges enjoyed by these elites discourage innovation and encourage poor scientific practices ${ }^{11}$. It is true that scientific elites have enormous power in the elaboration and orientation of science and innovation polices in China. The Medium to Long Term National Plan for the Development of Science and Technology (2006-2020), for example, is partly a result of a two-year consultation with more than 2,000 scientists and in the past, they have managed to persuade the authorities to increase spending on science and technology development (Cao, 2007). However, the privileges the scientific elites enjoy mean that they risk losing a degree of autonomy and independence and become more obedient to authority, with implications detrimental to science and innovation.

\section{3: Challenge 3: Open innovation vs techno-nationalism}

Corresponding to the fact that more firms are embracing 'open' innovation approaches and actively cooperating with actors outside the firm to gain access to new knowledge and commercialise their own knowledge, the internationalisation of innovation continues to accelerate and spread to an increasing number of countries. According to OECD (2008b), there has been significant increases in cross-border R\&D and international cooperation in scientific research and publication. In addition, multinational companies increasingly seek to source technology internationally and tap into centres of increasingly multidisciplinary knowledge worldwide. Also, it has become evident that a few emerging countries have become increasingly incorporated within the global innovation networks in recent years.

Increasing international mobility of workers and, in particular, of highly skilled science and technology workers, is one of the prominent features of internationalised innovation. Those involved spread their knowledge to colleagues when they move and there are also knowledge spillovers to others in the same location not only because of geographical proximity and social relationships but also through a 'community of practices' (Gertler, 2003) bound together by shared experiences and expertise.

Arguably China has seen some benefits as MNCs establish their R\&D centres in the country. In particular, the increasing number of returnees from the west in recent years suggests that the brain drain in one period may well become the source of 'brain regain' at a later date $(\mathrm{OECD}, 2008 \mathrm{c})$. Indeed, as stocks of repatriated scientists and engineers return in increasing numbers, one may wonder whether China is starting to see a wave of 'brain circulation' of the sort that South Korea experienced in an earlier period. This 'brain circulation' represents a complex and decentralised two-way flow of skills, capital and technology between different economies. The economic geographer Anna Lee Saxenian has recorded how the circulation of skilled workers from the Chinese diaspora has contributed to the development of high-tech industries and regions in China, transforming local institutions and improving local information exchanges there, while at the same time maintaining their social and professional ties to the science and technology communities in Silicon Valley (Saxenian, 2005).

There are, however, concerns over China's Medium to Long Term National Plan for the Development of Science and Technology (2006-2020). Because of the Plan's emphasis on 'independent innovation' (zizhu chuangxin) and China's policy in promoting key firms as 'national champions', there is some concern that China risks becoming overly inward-looking

\footnotetext{
${ }^{11}$ See, for example, http://www.scidev.net/en/news/chinas-scientific-elite-too-powerful.html.
} 
in relation to science and technology, impeding international collaborative innovation (e.g. Leadbeater and Wilsdon, 2007). One may even trace the origins of this back to Mao's selfreliance policies of the 1960s. Without a clear definition of 'independence' in the context of internationalised innovation, some observers wonder whether the implications of 'independent innovation' might include reduction in support for international collaboration (Wilsdon and Keeley, 2007).

However, speculation over 'independent innovation' may merely indicate a misunderstanding of China's policy and a mistranslation of zizhu chuangxin, which, as far as we are concerned, involves Chinese institutions and scientists merely playing a much more active and leading role in innovation instead of being passive recipients of imported technology. In addition, China is sufficiently aware of its diasporas' foreign relationships for it to benefit from brain circulation. Therefore, we suspect the emphasis on zizhu chuangxin does not necessarily involve China in withdrawing from the global innovation network.

\section{Conclusion}

China has been through a remarkable transition journey over the last three decades. There has been significant economic growth and improvement in living standards. The reforms cannot be turned back and the market is now playing an extremely important role in every corner of the economy. China is now a much more open country and people enjoy a much larger degree of freedom. On the other hand, the country is still ruled by the Communist Party and is faced with the formidable challenge of making its development more socially, economically and environmentally sustainable.

It seems that the Chinese authorities increasingly resort to science and innovation to face up to the country's challenges as evident in its Medium to Long Term National Plan for the Development of Science and Technology (2006-2020). Following up the Plan the highprofile 'One Thousand Talents Scheme' aims to attract global scientific elites to contribute to the country's science and technology development, with a particular focus on luring back top scientists of Chinese origin. The Scheme itself reflects the transition of the Chinese innovation system to a more open one on the one hand and, on the other, represents China's latest effort to boost its innovation capacity, taking advantage of the internationalisation of innovation and large pool of overseas Chinese talents.

With China's huge spending power and the opportunities its outstanding economic growth brings, the scheme seems to be working well with more than 800 high-level scientists and professionals since early 2009 having been lured back to China as a result of the scheme.. No doubt China has an advantage in mobilising resources and the returnees will help to energise and orchestrate innovation in China. However, whether this 'brain circulation' is a permanent feature and whether the transition of the Chinese innovation system is successful will depend on a number of factors beyond mere investment of financial resources. In particular, to enable global scientific elites to transplant the norms and values of world's learning centres of innovation to China, the Chinese innovation system needs to become more transparent, open and autonomous. In addition, there is a strong argument for the Chinese authorities to free global scientific elites from tight political control and to grant them a greater degree of independence and autonomy. Moreover, the Chinese need to clear the doubts around its emphasis on zizhu chuangxin and convince their foreign partners that they fully embrace the global innovation network and encourage international cooperation.

China is increasingly important in the global economy and it could have a disproportionate impact on the global innovation network in the long term. The future of its efforts in attracting global scientific elites will send a signal as to the direction of the country's future transition. 


\section{Reference:}

Cao, C. (2007) 'Chinese scientific elites and their political and social role', Modern Chinese Studies, 2007 (1)

Cao, C. (2010) A climate for misconduct, [online], available at: http://roomfordebate.blogs.nytimes.com/2010/01/18/will-china-achieve-science-supremacy/, accessed 26.8.2010

Cao, C. and Suttmeier, RP. (2001) 'China's new scientific elite: distinguished young scientists, the research environment and hopes for Chinese science', The China Quarterly (2001), 168: 960-984

CREST (2007) Internationalisation of $R \& D$ - Facing the Challenge of Globalisation: approaches to a proactive international policy in $S \& T$. [online], available at http://ec.europa.eu/invest-in-research/pdf/download en/report international.pdf Accessed 20.8.2010

Gertler, M. (2003), 'Tacit knowledge and the economic geography of context, or the undefinable tacitness of being (there)', Journal of Economic Geography, 2003(3):75-99

Lazonick, W. (2007), 'Foreign Direct Investment, Transnational Migration, and Indigenous Innovation in the Globalisation of High-tech Labour', revised version of paper presented at the International Forum of Comparative Political Economy of Globalisation, 1-3 September 2006, Remin University of China, Beijing

Leadbeater, C. and Wilsdon, J. (2007), The Atlas of Ideas: How Asian Innovation Can Benefit Us All. Demos: London

OECD (2008a) OECD Review of Innovation Policy: China. OECD, Paris

OECD (2008b) OECD Science, Technology and Industry Outlook. OECD, Paris

OECD (2008c) The Global Competition for Talent. OECD, Paris

Saxenian, A-L (2005), 'From brain drain to brain circulation: transnational communities and regional upgrading in India and China', Studies in Comparative International Development, 40 (2): $35-61$

Saxenian, A-L (2006), The New Argonauts, Harvard University Press, Cambridge, Massachusetts.

Wilsdon, J. and Keeley, J. 2007 China: The Next Science Superpower? Demos, [online], available at www.demos.co.uk, accessed 28.8.2010

Wyckoff, A. and Schapper, M. 2005, 'The Changing Dynamics of the Global Market for the Highly Skilled', [online], available at http://www.advancingknowledge.com/drafts/WyckoffVersion\%20Feb\%2028\%20-\%20Global HRST 7-Jan Draft.doc. Accessed 16.8.2010 